\title{
Variations in gastric compliance induced by acute blood volume changes in anesthetized rats
}

J.R.V. Graça, P.R.L. Leal, F.A.A. Gondim, F.H. Rola and A.A. Santos
Departamento de Fisiologia e Farmacologia, Faculdade de Medicina, Universidade Federal do Ceará, Fortaleza, CE, Brasil

\section{Correspondence}

A.A. Santos

Laboratório Escola Prof. Luiz Capelo

Departamento de Fisiologia e

Farmacologia, FM, UFC

Caixa Postal 3157

60430-270 Fortaleza, CE

Brasil

Fax: + 55-85-288-8333

E-mail: meno@ufc.br

Research supported by CAPES and CNPq scholarships and an FUNCAP research grant. This work is part of a Master's thesis presented by J.R.V. Graça to the Departamento de Fisiologia e Farmacologia, UFC, Fortaleza, CE, Brazil.

Received August 9, 2001 Accepted January 11, 2002

\section{Abstract}

The impact of acute volume imbalances on gastric volume $(\mathrm{GV})$ was studied in anesthetized rats (250-300 g). After cervical and femoral vessel cannulation, a balloon catheter was positioned in the proximal stomach. The opposite end of the catheter was connected to a barostat with an electronic sensor coupled to a plethysmometer. A standard ionic solution was used to fill the balloon (about $3.0 \mathrm{ml}$ ) and the communicating vessel system, and to raise the reservoir liquid level 4 $\mathrm{cm}$ above the animals' xiphoid appendix. Due to constant barostat pressure, GV values were considered to represent the gastric compliance index. All animals were monitored for $90 \mathrm{~min}$. After a basal interval, they were randomly assigned to normovolemic, hypervolemic, hypovolemic or restored protocols. Data were compared by ANOVA followed by Bonferroni's test. Mean arterial pressure (MAP), central venous pressure $(\mathrm{CVP})$ and $\mathrm{GV}$ values did not change in normovolemic animals $(\mathrm{N}=5)$. Hypervolemic animals $(\mathrm{N}=12)$ were transfused at $0.5 \mathrm{ml} / \mathrm{min}$ with a suspension of red blood cells in Ringer-lactate solution with albumin $(12.5 \mathrm{ml} / \mathrm{kg})$, which reduced $\mathrm{GV}$ values by $11.3 \%(\mathrm{P}<0.05)$. Hypovolemic rats $(\mathrm{N}=12)$ were bled up to $10 \mathrm{ml} / \mathrm{kg}$, a procedure that increased $\mathrm{GV}$ values by $15.8 \%(\mathrm{P}<0.05)$. In the restored group $(\mathrm{N}=12)$, shed blood replacement brought $\mathrm{GV}$ values back to basal levels in bled animals $(\mathrm{P}>0.05)$. MAP and CVP values increased $(\mathrm{P}<0.05)$ after hypervolemia but decreased $(\mathrm{P}<0.05)$ with hypovolemia. In conclusion, blood volume level modulates gastric compliance, turning the stomach into an adjustable reservoir, which could be part of the homeostatic process to balance blood volume.

\section{Key words} - Blood volume

- Gastric compliance

- Gastrointestinal motility

- Hemorrhage

- Hypervolemia
In a 1983 study on anesthetized dogs Capelo and co-workers (1) showed that gastric compliance was modulated by blood volume (BV) level, with hypervolemia decreasing stomach accommodation and hypovolemia making the stomach more compliant. In that study, the ratio between the saline volume infused into the stomach and the corresponding intraluminal pressure was used to monitor gastric compliance. The dogs were submitted to a standard sequence of BV changes, i.e., after a basal period they received saline infusion (about $50 \mathrm{ml} / \mathrm{kg}$ ) and were then bled (about $30 \mathrm{ml} / \mathrm{kg}$ ).

In order to further characterize this phenomenon, we decided to review this subject in the rat after developing a plethysmometric method that allowed continuous monitoring of gastric compliance (2). The present study reassesses the effect of $\mathrm{BV}$ imbalance on 
gastric compliance in rats not submitted to laparotomy or pylorus ligature. The protocol design was improved by keeping BV changes within the physiological range and by monitoring gastric volume (GV) both during and after each BV change. Hypervolemia was obtained by blood transfusion $(12.5 \mathrm{ml} / \mathrm{kg})$ while the effect of bleeding $(10 \mathrm{ml} / \mathrm{kg})$ on gastric compliance was studied in a separate group of rats. Other bled animals were transfused with their own previously shed blood. A preliminary report of part of this study was published in abstract form (3).

Male Wistar rats $(\mathrm{N}=39)$ weighing 250-300 g were obtained from our institution's breeding facilities. All animal handling was carried out according to the "Guide for Care and Use of Laboratory Animals", National Institutes of Health, Bethesda, MD, USA.

The animals were fasted for $24 \mathrm{~h}$ with free access to water and housed in individual Bowman cages to prevent coprophagy. After urethane anesthesia a tracheostomy was performed to assure free breathing. Femoral and cervical vessels were cannulated with polyethylene tubing filled with saline and heparin $(500 \mathrm{U} / \mathrm{ml})$. Jugular vein and carotid cannulae were used for hemodynamic monitoring and the femoral vessels were used for bleeding and blood infusion.

After surgery, a rubber balloon catheter was introduced per os and positioned in the proximal stomach. The opposite end of the catheter was connected to the bottom of a U-shaped reservoir (volume $30 \mathrm{ml}$; internal diameter $2.5 \mathrm{~cm}$ ) with an electronic volume sensor coupled to a plethysmometer (Ugo Basille, Comerio, Italy). The balloon (about $3 \mathrm{ml}$ ), the catheter and the reservoir were filled with a pre-warmed $\left(37^{\circ} \mathrm{C}\right)$ standard ionic solution [ $99.7 \mathrm{ml}$ of $45 \mathrm{mg} \% \mathrm{NaCl}$ and $0.3 \mathrm{ml}$ of Imbibente $\mathrm{BBC} 97^{\circledR}(75 \%$ water plus $15 \%$ polyethylene glycol; Ornano, Milan, Italy)]. The fluid level in the reservoir was kept $4 \mathrm{~cm}$ above the xiphoid process. Due to its nearly constant pressure, the reser- voir functions as a barostat and $\mathrm{GV}$ values can be considered to represent gastric compliance (2). Balloon volume shifts transmitted to the reservoir were continuously displayed by the plethysmometer. GV values (in $\mathrm{ml}$ ) were recorded at 1-min intervals.

Next, a 30-min period was allowed for gastric motility and hemodynamic parameter stabilization. All animals were monitored for a total of $90 \mathrm{~min}$. The first $20 \mathrm{~min}$ were considered to be the basal period, after which the animals were randomly submitted to one of the following experimental protocols.

Normovolemic group $(\mathrm{N}=5)$. In this group, the BV of the animals was left unchanged. Hemodynamic and GV data collected throughout the 90 min of monitoring were pooled into nine consecutive 10-min intervals.

Hypervolemic group $(\mathrm{N}=12)$. After the basal period, the animals were transfused $(0.5 \mathrm{ml} / \mathrm{min})$ with an isotonic, isoncotic and isohemic suspension up to a volume equivalent to $12.5 \mathrm{ml} / \mathrm{kg}$. Homologous erythrocytes obtained on the same day were suspended in Ringer-lactate solution with $0.6 \mathrm{~g} \%$ bovine serum albumin up to a final hematocrit of $50 \%$. GV and hemodynamic parameters were monitored during the basal period as well as during and after transfusion, respectively corresponding to the expansion and expanded periods. Data obtained during the $60 \mathrm{~min}$ of the expanded period were pooled into consecutive 10-min intervals, respectively named expanded 10, 20, 30, 40, 50 and 60.

Hypovolemic group $(\mathrm{N}=12)$. After the basal period, the animals were bled up to a volume equivalent to $10 \mathrm{ml} / \mathrm{kg}$. GV and hemodynamic parameters were monitored during the basal period as well as during and after bleeding, respectively corresponding to the retraction and retracted periods. Data obtained during the $60 \mathrm{~min}$ of the retracted period were pooled into consecutive 10-min intervals, respectively named retracted 10 , 20, 30, 40, 50 and 60. 
Restored group $(\mathrm{N}=10)$. After the basal period, the animals were bled up to a volume equivalent to $10 \mathrm{ml} / \mathrm{kg}$. The shed blood was kept inside a heparinized syringe in a bath at $37^{\circ} \mathrm{C}$. Ten minutes later this blood was infused back into the animals at a rate of 0.5 $\mathrm{ml} / \mathrm{min}$. GV volume and hemodynamic parameters were monitored during the basal interval, during and after bleeding as well as during and after blood reinfusion, respectively corresponding to the retraction, retracted, restoration and restored periods. Data obtained during the $40 \mathrm{~min}$ of the restored period were divided into four consecutive 10min intervals, respectively named restored 10, 20, 30 and 40.

The Evans blue method was used to measure plasma volume. The dye concentration was determined by spectrophotometry at 560 nm (Jena, Germany). After hematocrit correction, $\mathrm{BV}$ values are reported as $\mathrm{ml}$ per $100 \mathrm{~g}$ body weight. Mean arterial pressure (MAP, in $\mathrm{mmHg}$ ) and central venous pressure $\left(\mathrm{CVP}\right.$, in $\left.\mathrm{cmH}_{2} \mathrm{O}\right)$ were continuously recorded with a polygraph (Narco BioSystems, Houston, TX, USA).

Data are reported as mean \pm SEM. GV values are presented as box and whisker plots. Analysis of variance (ANOVA) followed by Bonferroni's test was used to compare differences in mean values between the basal and experimental periods. $\mathrm{P}$ values lower than 0.05 were considered to be statistically significant.

No significant differences in GV or in hemodynamic data were observed among the normovolemic, hypervolemic, hypovolemic and restored animals during the basal period.

Normovolemic animals displayed spontaneous fluctuation of $\mathrm{GV}$ values during monitoring. However, the changes between nine consecutive 10-min intervals were not significant $(2.88 \pm 0.14,2.85 \pm 0.13,2.86 \pm$ $0.13,2.85 \pm 0.13,2.85 \pm 0.12,2.84 \pm 0.14$, $2.86 \pm 0.13,2.85 \pm 0.12$ and $2.85 \pm 0.14 \mathrm{ml}$, respectively). The same was true $(\mathrm{P}>0.05)$ for MAP values $(104.8 \pm 2.2,104.0 \pm 0.6$, $105.2 \pm 2.1,106.4 \pm 2.3,104.4 \pm 1.5,103.4$ $\pm 2.0,104.2 \pm 1.7,104.6 \pm 1.5,106.6 \pm 2.9$ $\mathrm{mmHg})$ as well as for CVP $(0.4 \pm 0.2,0.1 \pm$ $0.2,-0.1 \pm 0.2,-0.2 \pm 0.3,0.1 \pm 0.2,0.6 \pm 0.2$, $0.7 \pm 0.2,0.4 \pm 0.1,0.0 \pm 0.3 \mathrm{cmH}_{2} \mathrm{O}$ ). Hematocrit and mean BV values of the normovolemic group were $56 \%$ and $7.2 \mathrm{ml}$ per $100 \mathrm{~g}$ body weight, respectively.

Figure 1A shows that acute hypervolemia decreased gastric compliance. Compared to basal values $(2.93 \pm 0.07 \mathrm{ml}), \mathrm{GV}$ started to decrease already during transfusion ( 2.74 $\pm 0.08 \mathrm{ml}$ ), with the reduction becoming significant $(2.60 \pm 0.06 \mathrm{ml})$ only after transfusion and continuing as such during the subsequent 10-min intervals of the expanded period $(2.59 \pm 0.06,2.57 \pm 0.06,2.58 \pm 0.08$, $2.58 \pm 0.09$ and $2.57 \pm 0.08 \mathrm{ml}$, respectively, $\mathrm{P}<0.05)$. MAP and CVP values increased $(\mathrm{P}<0.05)$ during expansion, remaining as such until the "expanded 20" interval and then returning to basal levels.

Figure 1B shows that acute hypovolemia decreased gastric compliance. Compared to basal values $(2.85 \pm 0.12 \mathrm{ml}), \mathrm{GV}$ started to increase during bleeding $(3.02 \pm 0.11 \mathrm{ml})$, with the increase becoming significant (3.30 $\pm 0.10 \mathrm{ml}$ ) only during the "bled 10 " interval. $\mathrm{GV}$ values remained increased $(\mathrm{P}<0.05)$ during the subsequent intervals of the retracted period $(3.29 \pm 0.10,3.29 \pm 0.10,3.39 \pm 0.08$, $3.39 \pm 0.07$ and $3.39 \pm 0.07 \mathrm{ml}$, respectively, $\mathrm{P}<0.05)$. MAP and CVP values also decreased $(\mathrm{P}<0.05)$ during $\mathrm{BV}$ retraction and remained below basal levels throughout the bled period.

Figure 1C presents the effects of hemorrhage followed by blood replacement on gastric volume. Compared to basal values $(2.90 \pm 0.06 \mathrm{ml}), \mathrm{GV}$ increased during blood volume retraction $(3.09 \pm 0.07 \mathrm{ml}, \mathrm{P}>0.05)$ and reached significant levels in the retracted period $(3.32 \pm 0.07 \mathrm{ml})$. During blood replacement, $\mathrm{GV}$ remained above basal levels (3.24 $\pm 0.07 \mathrm{ml}, \mathrm{P}<0.05)$. Twenty minutes after blood volume restoration, $\mathrm{GV}$ values 
returned to basal levels $(2.98 \pm 0.07 \mathrm{ml}$, $\mathrm{P}>0.05)$ and remained as such for at least 40 $\min (2.70 \pm 0.10$ and $2.64 \pm 0.09 \mathrm{ml}$, respectively). Hemorrhage also decreased MAP and CVP values, which remained below basal levels during the retracted period $(\mathrm{P}>0.05)$.

The present data show that BV levels modulate gastric compliance. Acute hypervolemia made the stomach less compliant, an effect that was demonstrable already during transfusion, attained significant values shortly afterwards and remained as such during the $60 \mathrm{~min}$ of the expanded period. Acute hypovolemia increased gastric compliance, an effect that started during bleeding and became significant thereafter, with a return to normal values after blood replacement. This confirms our previous observations on dogs (1) and extends them to another animal species, i.e., the rat. Gastric compliance was monitored continuously by a reliable method in which gastric balloon volume and ple-
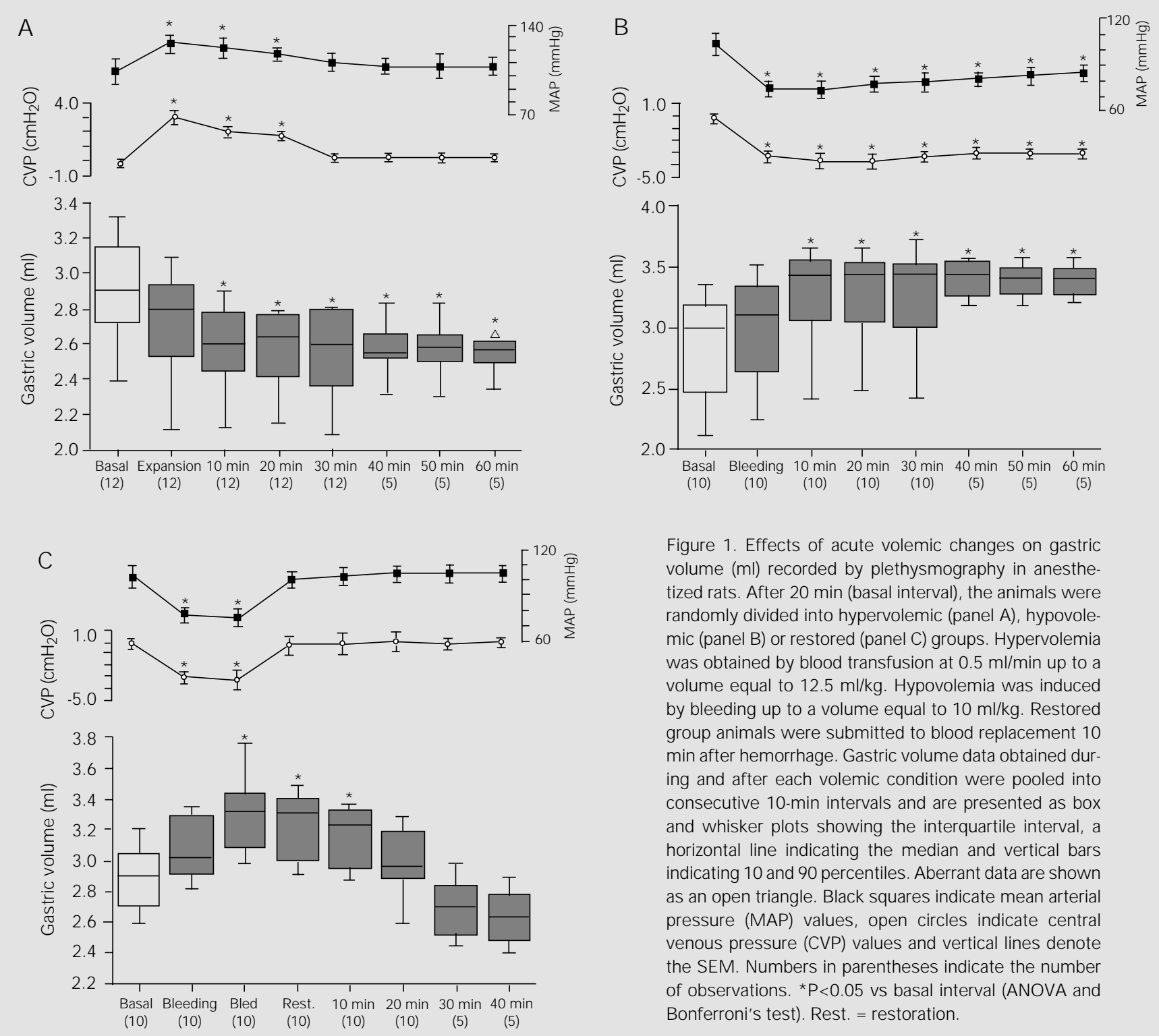

Figure 1. Effects of acute volemic changes on gastric volume $(\mathrm{ml})$ recorded by plethysmography in anesthetized rats. After $20 \mathrm{~min}$ (basal interval), the animals were randomly divided into hypervolemic (panel A), hypovolemic (panel B) or restored (panel C) groups. Hypervolemia was obtained by blood transfusion at $0.5 \mathrm{ml} / \mathrm{min}$ up to a volume equal to $12.5 \mathrm{ml} / \mathrm{kg}$. Hypovolemia was induced by bleeding up to a volume equal to $10 \mathrm{ml} / \mathrm{kg}$. Restored group animals were submitted to blood replacement 10 min after hemorrhage. Gastric volume data obtained during and after each volemic condition were pooled into consecutive 10-min intervals and are presented as box and whisker plots showing the interquartile interval, a horizontal line indicating the median and vertical bars indicating 10 and 90 percentiles. Aberrant data are shown as an open triangle. Black squares indicate mean arterial pressure (MAP) values, open circles indicate central venous pressure (CVP) values and vertical lines denote the SEM. Numbers in parentheses indicate the number of observations. $* \mathrm{P}<0.05$ vs basal interval (ANOVA and Bonferroni's test). Rest. $=$ restoration. 
thysmometric readings were strongly correlated (2).

The adverse effects of saline infusion on gastric smooth muscle tonus (hemodilution, acidosis or serum electrolyte imbalance) were avoided by transfusing 3 to $4 \mathrm{ml}$ of reconstituted blood to produce a $17.8 \% \mathrm{BV}$ expansion similar to that elicited by sudden postural changes (4). BV retraction, on the other hand, was obtained by free bleeding up to $14.3 \%$ of total BV instead of a controlled hemorrhage up to a predetermined drop of arterial pressure as described by Wiggers (5). This choice is relevant since it mimics the nature of hemorrhage in the clinical setting, allowing the full effects of compensatory neurohumoral mechanisms that tend to restore arterial pressure and $\mathrm{BV}$ while minimizing the occurrence of hemorrhagic enteritis (6). It should be noted that almost symmetrical gastric compliance modifications followed acute BV changes. GV variations after BV expansion were similar (in absolute values) to those obtained after BV retraction (a $-11.3 \%$ decrease $v s$ a $+15.8 \%$ increase, respectively). The hemodynamic data presented in Figure 1 are comparable to those described in rats by others $(7,8)$.

In mammals, the gastrointestinal tract is the main route for salt and water entry. However, the prevalent view holds that BV balance relies solely on the functional relationship between the cardiovascular system and the kidney (9). However, there is a growing body of clinical and experimental evidence indicating an active role of the gut in BV homeostasis. The gut seems to react to BV imbalances, at least the acute ones, by adjusting both its motility and permeability to fluid and electrolytes (10).

Hypervolemia increases intestinal secretion of fluid and electrolytes while minimizing their absorption (11). On the other hand, bleeding, dehydration or reduced salt ingestion maximizes salt and water intestinal absorption while decreasing or even halting secretion (12). Adjustments in the bowel handling of fluid and electrolytes are essential to hemodynamic stability after bleeding: the immediate survival and BV replacement are jeopardized when animals are previously submitted to fasting (8). The intestinal permeability appears to be BV dependent. Even passive postural changes modify the gut epithelium absorption/secretion ratio: orthostasis maximizes intestinal salt and water absorption in healthy volunteers while tilting minimizes absorption and increases secretion (13).

Gut motor behavior is also modified by $\mathrm{BV}$ imbalances. We have shown that jejunal compliance is also modulated by BV levels, decreasing after expansion and increasing after retraction (14). Since the proximal stomach tonus drives gastric fluid emptying, BV changes may modify the flow through the gastroduodenal segment (15). However, the gastric emptying rate and the gastrointestinal transit of a liquid meal in awake rats are decreased by hypervolemia and increased after hypovolemia $(16,17)$. This apparent discrepancy can be understood if one considers the breaking effect of duodenal motility on gastric emptying (15). It has also been shown that bleeding reduces both the amplitude and frequency of duodenal contractions in anesthetized rats. This effect persisted up to $1 \mathrm{~h}$ after bleeding and was reversed by blood reinfusion (18).

The effects of hemorrhage on gut motor function, although studied since the forties, have not yet been established. It was reported that arterial hypotension reduced or even abolished the upper gut motility while others observed increased small intestine motility (4). Hemorrhage decreases nutrient and oxygen supply to tissues, a fact that could explain gut motility inhibition. However, in vivo ischemia is buffered by potent mechanisms due to the autoregulation of the splanchnic vessels and their extensive anastomosis (19). Moreover, severe gut hypoxia is observed only when splanchnic blood flow drops to $60 \%$, an event representing a $75 \%$ 
drop in cardiac output (20). On the other hand, few studies on gut motor behavior under hypervolemic conditions are available. Neural or humoral pathways, or both may mediate gastric smooth muscle tonus changes induced by acute BV imbalances. The fast onset (within minutes) of gastric compliance changes suggests a neural mechanism. Humoral factors released by blood volume imbalances may also play a role in GV variations. Studies are under way to outline the neuroautonomic pathways involved in the phenomena described here.

The present study shows that gastric com- pliance is BV dependent, suggesting the existence of a mechanism that functionally involves the gastrointestinal tract and the cardiovascular system to cope with acute blood volume imbalances.

\section{Acknowledgments}

We thank Prof. Glauce Viana and Prof. Ronaldo Ribeiro for providing access to their laboratory facilities. We are indebted to Prof. Marcus Vale for reviewing the text and to Mr. Haroldo Pinheiro for his technical assistance.

\section{References}

1. Capelo LR, Cavalcante DM, Leitão IA, Filho GC \& da-Silva EAT (1983). Modifications of gastric compliance in dogs related to changes of extracellular fluid volume. Brazilian J ournal of Medical and Biological Research, 16: 73-76.

2. Graça J RV, Leal PRL, Gondim FdeAA, Rola FH \& Santos AA (2000). A plethysmometric method for gastric compliance studies in anesthetized rats. J oumal of Pharmacological and Toxicological Methods, 43: 25-30.

3. Graça J RV, Leal PRL, Rola FH \& Santos AA (1999). Neural mechanisms involved in gastric compliance modifications due to acute volemic changes in anesthetized rats. Neurogastroenterology and M otility, 11: 261 (Abstract).

4. Persson PB (1996). Modulation of cardiovascular control mechanisms and their interaction. Physiological Reviews, 76: 193244.

5. Wiggers CJ (1950). Experimental hemorrhagic shock. In: Physiology of Shock. The Commonwealth Found, New York, NY, USA, 121-146.

6. Swan H \& Nelson AW (1971). Experimental lethal canine hemorrhage: ischemic abdominal viscera; absence of hemorrhagic gut or portal congestion. J ournal of Surgical Research, 11: 620-628.

7. Nose H, Yamada S \& Marimoto T (1984). Transvascular fluid shift and thoracic duct lymph: analysis of lymph formation in the rat. J apanese J ournal of Physiology, 34: 713-729.
8. Darlington DN, J ones RO, Magnuson TA \& Gann DS (1993). Role of intestinal fluid in restitution of blood volume and plasma protein after hemorrhage in awake rats. American J ournal of Physiology, 268: R715-R722.

9. Guyton AC \& Hall J E (2000). Integration of renal mechanisms for control of blood volume and extracellular fluid volume. In: Textbook of Medical Physiology. 10th edn. W.B. Saunders, Philadelphia, PA, USA, 329-345.

10. Michell AR (1996). The gut: the unobstructive regulator of sodium balance. Perspectives in Biology and Medicine, 29: 203213.

11. Higgins J r J T \& Blair NP (1971). Intestinal transport of water and electrolyte during extracellular fluid volume expansion in dogs. J ournal of Clinical Investigation, 30: 2569-2579.

12. Levens NR (1985). Control of intestinal absorption by the renin-angiotensin system. American J ournal of Physiology, 249: G3-G15.

13. Sjövall $H$, Abrahamsson $H$, Westlander $G$, Gillberg R, Redfors S, J odal M \& Lundgren Ö (1986). Intestinal fluid and electrolyte transport in man during reduced circulating blood volume. Gut, 27: 913-918.

14. Rola FH, Santos AA, Xavier-Neto J, Cristino-Filho G, Rocha Cl, Santiago-J rAT, Gondim FAA, Pereira J M \& Capelo LR (1989). Effects of acute volemic changes on jejunal compliance in dogs. Brazilian $\mathrm{J}$ ournal of Medical and Biological Re- search, 22: 523-531.

15. Mayer EA (1994). The physiology of gastric storage and emptying. In: J ohnson LR (Editor), Physiology of the Gastrointestinal Tract. 3rd edn. Raven, New York, NY, USA, 929.

16. Gondim FdeAA, Oliveira GR, Graça J RV, Gondim RBM, Alencar HMP, Dantas RP, Santos AA \& Rola FH (1999). Neural mechanisms involved in the delay of gastric emptying of liquid elicited by acute blood volume expansion in awake rats. Neurogastroenterology and Motility, 11: 93-99.

17. Oliveira GR, Gondim FdeAA, Graça J RV, Xavier-Neto J, Dantas RP, Gondim RB, Santos AA \& Rola FH (1998). Acute blood volume expansion delays the gastrointestinal transit of a charcoal meal in awake rats. Brazilian J ournal of Medical and Biological Research, 31: 835-840.

18. Limlomwongse $L$, Suanarunsawat $T \&$ Krishnamra N (1988). Hemorrhage with blood reinfusion and the relationship between gastroduodenal motility and bile reflux in rats. Canadian J ournal of Physiology and Pharmacology, 66: 608-612.

19. Granger HJ \& Norris CP (1980). Intrinsic regulation of intestinal oxygenation in the anesthetized dog. American J ournal of Physiology, 238: H836-H843.

20. Landow L \& Anderson LW (1994). Splanchnic ischaemia and its role in multiple organ failure. Acta Anaesthesiologica Scandinavica, 38: 626-639. 